\title{
KONSEP KEPEMIMPINAN SOEHARTO DALAM BUTIR-BUTIR BUDAYA JAWA
}

\author{
Wachid Eko Purwanto \\ Universitas Ahmad Dahlan \\ wachid.purwanto@pbsi.uad.ac.id \\ Naskah diterima: 20 Januari 2017; direvisi: 20 April 2017; disetujui: 21 April 2017
}

\begin{abstract}
This study aimed to describe (1) the concept of leadership in pituduh that fit into the category ketuhunan and (2) the concept of leadership in wewaler (Prohibition). This research is the study of literature. The method used in this study is a content analysis method. The object of this study is the concept of Suharto. The subjects were Unen-Unen (proverb). Data collected with a note reading techniques. The primary data source is selected by using purposive sampling method. The conclusions made by the formulation and the conclusion of the data that has been analyzed and interpreted with the use of the theory of Paul Ricoeur hermeneutics. The results of this study are as follows. First, the concept of leadership in pituduh (hint) that fit into the category of divinity has two leadership instructions: (1) be applicable authorities properly, (2) the truth of God into a basic truth of the ruler. The concept of leadership in pituduh (hint) that fit into the category of nationality include (1) a good leader is a dreamer fair, spirited noble, able to give jobs to the people, (2) A good leader is a leader who can reassure the people, (3) A good leader is willing and able to fix the flaws and vices, (4) leadership is a trust from God, (5) A good leader wary of praise, (6) a good leader wary of bad temper, (7) the leader of the evil is the leader dangerous, (8) Choosing a good leader is not an evil leader, (9) the evil leader will declare evil is goodness. Second, the concept of leadership in wewaler (Prohibition) includes two categories, namely humanity and nationality. Category prohibition in humanitarian terms include a ban on the leaders of banned arrogant leader. The prohibition in respect of nationality shows that good leaders leaned pleasure and sadness on the basis pleasure and pain the people, not on personal pleasure and pain.
\end{abstract}

Keywords: Leadership, Suharto, Unen-Unen, Javanese culture

\begin{abstract}
ABSTRAK
Penelitian ini bertujuan untuk mendeskripsikan (1) konsep kepemimpinan dalam pituduh yang masuk ke dalam kategori ketuhunan dan (2) konsep kepemimpinan dalam Wewaler (Larangan). Penelitian ini adalah penelitian studi kepustakaan. Metode yang digunakan dalam penelitian ini adalah metode analisis konten. Objek penelitian ini adalah konsep kepemimpinan Soeharto. Subjek penelitian ini adalah unen-unen (pepatah). Teknik pengumpulan data dilakukan dengan teknik baca catat. Sumber data primer dipilih dengan menggunakan metode purposive sampling. Simpulan dilakukan dengan melakukan perumusan dan penyimpulan terhadap data yang telah dianalisis dan diinterpretasikan dengan pemanfaatan teori hermeneutika Paul Ricoeur. Hasil penelitian ini adalah sebagai berikut. Pertama, konsep kepemimpinan dalam pituduh (Petunjuk) yang masuk ke dalam kategori ketuhanan memiliki dua petunjuk kepemimpinan yakni (1) jadilah penguasa yang berlaku baik dan benar, (2) Kebenaran Tuhan menjadi dasar kebenaran penguasa. Konsep
\end{abstract}


kepemimpinan dalam pituduh (Petunjuk) yang masuk ke dalam kategori kebangsaan meliputi (1) pemimpin yang baik adalah pemimpi yang adil, berjiwa mulia, mampu memberi pekerjaan kepada rakyat, (2) Pemimpin yang baik adalah pemimpin yang mampu menenteramkan hati rakyat, (3) Pemimpin yang baik mau dan mampu memperbaiki kekurangan dan keburukan, (4) kepemimpinan adalah amanah dari Tuhan, (5) Pemimpin yang baik waspada terhadap pujian, (6) pemimpin yang baik waspada terhadap perangai buruk, (7) Pemimpin jahat adalah pemimpin yang berbahaya, (8) Memilih pemimpin yang baik bukan pemimpin jahat, (9) pemimpin yang jahat akan menyatakan kejahatan adalah kebaikan. Kedua, konsep kepemimpinan dalam Wewaler (Larangan) meliputi dua kategori, yakni kemanusiaan dan kebangsaan. Kategori larangan dalam hal kemanusiaan meliputi larangan terhadap pemimpin yakni pemimpin dilarang sombong. Larangan dalam hal kebangsaan menunjukkan bahwa pemimpin yang baik menyandarkan kesenangan dan kesedihannya atas dasar kesenangan dan kesedihan rakyatnya, bukan berdasar kesenangan dan kesedihan pribadi.

Kata kunci: Kepemimpinan, Soeharto, unen-unen, Budaya Jawa

\section{PENDAHULUAN}

Butir-butir Budaya Jawa: Hanggayuh Kasampurnaning Hurip, Berbudi Bawaleksana, Ngudi Sejatining Becik (selanjutnya akan disingkat menjadi BBBJ) merupakan sebuah judul buku yang disusun oleh Soeharto. Buku ini selesai disusun pada hari Rabu Kliwon tanggal 13 Juli 1983. Selanjutnya diterbitkan untuk umum pada tanggal 26 Desember 1987. Buku ini memuat kearifan lokal masyarakat Jawa dalam bentuk unen-unen (pepatah). Soeharto menyusun buku ini dengan niat sebagai pegangan hidup bagi anak-anaknya. Buku ini tersusun dalam dua bab utama, yakni Pituduh (Petunjuk) dan Wewaler (Larangan). Dua bab utama tersebut masing-masing terdiri atas beberapa subbab Ketuhanan Yang Maha Esa, Kemanusiaan, Kebangsaan, Kekeluargaan dan Kebendaan. Adapun sumber referensi yang digunakan sebagai sumber acuan buku ini adalah ajaran turunmenurun, serat Centhini, Cipto Hening dalam naskah Arjunawiwaha, Ronggowarsito (Serat Paramayoga, Pustaka Raja Purwa, Aji Pamasa, Cemporet, Jakalodang, wiris, witaradya, bharatayudha, kalatidha), Jayabaya, Serat Nitisastro, Suluk Selo, Tri Dharma Pengeran Samber Nyawa, Sera Wedatama, dan Serat Wulangreh.
Sebagai seorang presiden yang memimpin wilayah negara Indonesia, Soeharto memasukkan unen-unen Jawa yang memuat ajaran-ajaran kepemimpinan dalam buku BBBJ tersebut. Unen-unen adalah kalimat sederhana, singkat, padat dan jelas dengan susunan kata-kata yang indah runtut, sehingga mudah diingat dan dipahami (Sutanto, 2013:45). Dengan demikian, unen-unen (dalam bahasa Indonesia biasa disebut dengan pepatah) menjadi alat yang tepat guna menyampaikan ajaran kepemimpinan.

Sebagai presiden dengan latar belakang budaya Jawa, Soeharto tampaknya tidak dapat melepaskan diri dari konsep kepemimpinan Jawa. Konsep kepemimpinan Jawa merupakan konsep kekuasaan raja (ratu) yang dimengerti sebagai orang yang memusatkan suatu takaran kekuatan kosmis dalam dirinya, sebagai orang yang sakti sesakti-saktinya (Suseno, 1993:100). Dengan demikian, kekuasaan raja kentara dengan keteraturan dan kesuburan masyarakat dan alam. Kekuasaan raja terbukti apabila tidak ada lagi kekacauan, kritik, perlawanan, pemberontakan, gangguan ketentraman dan keselarasan (Suseno, 1993:101). Hal inilah yang kemudian disebut sebagai keadaan tata tentrem karta raharja (aturan tentram 
membuat sejahtera) sebagai harapan masyarakat Jawa kepada pemimpinnya.

Guna mencapai harapan tata tentrem karta raharja (aturan tentram membuat sejahtera), masyarakat Jawa memiliki unen-unen (pepatah) dalam bentuk pepatah yang memuat petuah atau ajaran bagaimana memimpin masyarakat hingga mencapai tahap tersebut. hal inilah yang kemudian dipakai oleh Soeharto dalam BBBJ. Tujuan penelitian ini untuk mendeskripsikan dua hal berikut. (1) Macam pituduh (petunjuk) kepemimpinan dalam Butir-Butir Budaya Jawa. (2) Macam wewaler (larangan) kepemimpinan dalam Butir-Butir Budaya Jawa.

\section{PEMBAHASAN}

Paul Ricoeur adalah tokoh yang berpengaruh besar di dalam perkembangan studi hermeneutika di era kontemporer. Beberapa pokok pemikiran Paul Ricoeur tentang hermeneutika diuraikan berdasarkan permasalahan awal sebagai berikut. Bagaimana sebuah pemikiran mengenai simbol, yang sedemikian luasnya dan sedemikian kuatnya, dapat membuka wawasan berpikir yang sejalan dengan arus rasionalitas dan ketatnya pemikiran filsafat? Singkatnya, bagaimana pemikiran filosofis dapat diartikulasikan berdasarkan hermeneutika simbol? Apabila orang mempermasalahkan simbol "sekarang" sebagai suatu periode historis, dia juga berhubungan langsung dengan modernitas. Aspek historis filsafat simbol sekaligus momen untuk melupakan dan merestorasi. Proses melupakan ini mengimbangi tugas yang dibebankan kepada manusia dan sekaligus memuaskan kebutuhan manusia melalui kontrol alam. Melupakan berarti pula merestorasi integritas bahasa. (Ricoeur dalam Indraningsih, 2011: 119)

Dari waktu ke waktu, bahasa yang digunakan sehari-hari berkembang menjadi logika simbolik. Kini saatnya orang menyegarkan kembali bahasa yang berawal dari kepenuhan bahasa. Menurut Paul Ricoeur, simbol membangkitkan pemikiran. Simbol memberi makna, namun makna yang diberikan tersebut adalah hal yang harus dipikirkan. Ricoeur juga mengemukakan kriteria simbol. Simbol berangkat dari sebuah kesaksian yang merupakan ranah pengalaman sebelum masuk ke dalam ranah teologi atau mitos. Simbol primer dalam hal ini adalah unsur bahasa yang harus dibedakan dengan simbol mitis. Simbol mitis lebih banyak diceritakan, menciptakan ruang bagi dimensi naratif, misal penokohan, latar tempat dan waktu di dalam fabel. (Ricoeur dalam Indraningsih, 2011: 119)

Tidak semua tanda (sign) merupakan simbol. Simbol mensyaratkan intensionalitas ganda. Pertama, intensionalitas literal, yaitu tanda secara konvensional mengimplikasikan pemaknaan yang melampaui simbol alam. Kedua, simbol haruslah membuat orang beranalogi dengan terus-menerus memberikan analognya. Simbol selalu bergerak dari makna awal dan terus melibatkan orang dalam proses simbolisasi. Simbol selalu melahirkan makna berikutnya - bahkan tersebab kedinamisan tersebut - simbol adalah perusak bagi simbol sebelumnya. Di dalam linguistik, aspek semantik simbol membuka sebuah revolusi makna (Ricoeur dalam Indraningsih, 2011: 119)

Bagaimana hubungan hermeneutika dengan pemikiran filosofis? Menurut Ricoeur, ada tiga tahap pemahaman yang menyebabkan perubahan dari kehidupan yang berada di dalam simbol menjadi cara berpikir yang berawal dari simbol. Pertama adalah fenomenologi sederhana yang berawal dari pemahaman simbol oleh dan dari simbol itu sendiri (totalitas simbol). Tahap pertama ini pun sudah merupakan pemahaman karena tahap ini telah menghubungkan simbol dengan dunia. Pemahaman pada tahap ini masih bersifat horisontal dan panoramik, belum menampakkan kedalaman. Orang harus melangkah pada tahap yang memungkinkannya untuk secara intens dan emosional sekaligus kritis pada saat yang bersamaan. Kita harus mengikuti proses penafsiran dan terlibat dalam kehidupan 
sebuah simbol atau mitos. (Ricoeur dalam Indraningsih, 2011: 119)

Pada tahap kedua, orang masuk pada ranah hermeneutik yang menawarkan apa yang disebut lingkaran hermeneutik. Interpretasi sangat tergantung pada keadaan individual. Dalam hermeneutika modern, simbol itu sendiri memberikan makna dan bekerja bersama-sama dengan inisiatif yang cerdas untuk menguraikannya. Hermeneutika mengajak orang untuk bersama-sama berperan dalam dinamika simbol yang menjadi subjek yang ditaklukkan. Hanya melalui peran bersama itulah pemahaman masuk ke dalam dimensi kritik dan akhirnya menjadi hermeneutika.

Selanjutnya, orang akan masuk ke dalam lingkaran hermeneutika. You must understand in order to believe, but you must believe in order to understand (Ricoeur dalam Indraningsih, 2011: 120). Pendapat ini menantang karena orang yang memahami tidak akan sampai pada kedekatan dengan apa yang dikatakan oleh teks apabila dia tidak hidup di dalam aura dari hal-hal yang dipahaminya. Lingkaran hermeneutika bergerak dari prapemahaman, melewati penafsiran, dan berusaha sampai kepada pemahaman.

Tahap ketiga adalah pemahaman simbol-simbol. Tahap inilah yang disebut dengan tahap filosofis. Pada tahap ini, pemikiran berawal dari simbol dan tentang simbol yang membangun pernyataan dasar bagi wacana yang hidup di antara manusia. Simbol membangkitkan pikiran sehingga kita harus selalu menghadapi pengulangan simbol dan tiruannya dalam rasionalitas, merasionalisasikan simbol, serta memastikan keberadaannya dalam imajinasi, tempat simbol itu lahir dan membentuk dirinya.

Hermeneutika mensyaratkan adanya interpretasi kreatif. Biarkan simbol itu dimaknai sebagai teka-teki (enigma), tetapi dengan awal seperti itu, simbol menampilkan makna, memberikan bentuknya dalam pemikiran sistematis dan otonom. Pemikiran yang berawal dari sim- bol mengandung dua hal, yaitu refleksi dan spekulasi. Refleksi adalah demitologisasi, yaitu reduksi mitos menjadi alegori (kiasan). Pemikiran reflektif berada dalam pertentangan dengan pemikiran spekulatif yang ingin menyimpan simbol dan mempertimbangkan keutamaannya. (Ricoeur dalam Indraningsih, 2011: 120).

Dengan demikian, secara lebih singkat dapat dikatakan bahwa langkah hermeneutika Ricoeur ada tiga tahap sebagai berikut. Pertama, langkah simbolik (tahap semantik). Langkah ini merupakan tahap pemahaman dari simbol ke simbol. Kedua, langkah hermeneutik (tahap reflektif). Langkah ini merupakan langkah pemberian makna terhadap simbol. Ketiga, langkah filosofis (tahap eksistensial). Langkah ini berupaya untuk merasionalkan simbol secara filosofis.

Diksi kuwasa (kuasa) dan penguwasa (penguasa/pemimpin) merupakan simbol konsep kepemimpinan Soeharto yang termaktub di dalam unen-unen di buku Butir-butir Budaya Jawa. Dua simbol inilah yang menjadi dasar pembahasan dalam penelitian ini. Dua simbol tersebut terdapat dalam dua tema yakni pituduh (petunjuk) dan wewaler (pantangan). Dalam tema pituduh, simbol kuwasa (kuasa) dan penguwasa (penguasa/pemimpin) yang dibahas dalam penelitian ini terdapat dalam dua subtema, yakni ketuhanan dan kebangsaan. Adapun wewaler terdapat dalam subtema kemanusiaan dan kebangsaan. Berikut adalah pembahasan konsep kekuasaan Soeharto dalam Butir-Butir Budaya Jawa dengan menggunakan tiga langkah hermeneutika Ricoeur. Pertama, langkah simbolik (tahap semantik). Langkah ini merupakan tahap pemahaman dari simbol ke simbol. Kedua, langkah hermeneutik (tahap reflektif). Langkah ini merupakan langkah pemberian makna terhadap simbol. Ketiga, langkah filosofis (tahap eksistensial/ontologism). Langkah ini berupaya untuk merasionalkan simbol secara filosofis. 
1. Pituduh (petunjuk)

Kekuasaan Soeharto yang dibahas dalam tema pituduh terdapat dalam subtema ketuhanan dan kebangsaan. Berikut masing-masing pembahasan tersebut.

a. Ketuhanan

Simbol kuwasa dan penguwasa dalam subtema ini meliputi dua unen-unen yang akan dibahas sebagai berikut.

1) Simbol kuwasa

Berikut adalah kutipan unenunen yang memuat simbol kuwasa dalam subtema Ketuhanan tersebut.

Ing donya iki ana rong warna sing diarani bener, yakuwi bener mungguhing Pangeran lan bener saka kang lagi kuwasa (Soeharto, 1987: 8)

a) Langkah simbolik

Simbol dalam unen-unen ini adalah kuwasa. Secara semantis unen-unen tersebut dapat dipahami sebagai berikut. Di dunia ini ada dua macam kebenaran, yaitu benar menurut Tuhan dan benar menurut yang sedang berkuasa. Berdasarkan hal tersebut, simbol kuwasa dalam unen-unen ini memiliki makna berkuasa.

b) Langkah hermeneutik

Di dunia ini ada dua macam kebenaran, yaitu benar menurut Tuhan dan benar menurut yang sedang berkuasa. Terjemahan semantis simbol kuwasa dalam unen-unen ini berarti berkuasa. Secara hermeneutik, dapat disebutkan bahwa pemimpin yang sedang berkuasa menguasai kebenaran. Penguasaan atas kebenaran ini disejajarkan dengan kekuasaan Tuhan.

c) Langkah filosofis
Di dunia ini ada dua macam kebenaran, yaitu benar menurut Tuhan dan benar menurut yang sedang berkuasa. Pada tahap hermeneutik, disebutkan bahwa pemimpin yang sedang berkuasa menguasai kebenaran. Penguasaan atas kebenaran ini disejajarkan dengan kekuasaan Tuhan. Hal ini secara filosofis berarti bahwa kekuasaan pemimpin yang sedang berkuasa sejajar dengan kekuasaan Tuhan. Dengan demikian, kekuasaan pemimpin adalah mutlak. Meskipun demikian, kemutlakan kekuasaan pemimpin tersebut terbatas. Kalimat lan bener saka kang lagi kuwasa (dan benar menurut yang sedang berkuasa) mengandung unsur filosofis bahwa pemimpin yang sedang berkuasa bisa saja berlaku benar sesuai kebenaran yang datang dari Tuhan, namun juga bisa berlaku membenarkan diri sendiri atas perbuatannya yang tidak benar. Dengan demikian, kebenaran menurut penguasa ada dua yakni kebenaran menurut Tuhan dan kebenaran menurut dirinya sendiri.

2) Simbol kuwasa

Berikut adalah kutipan unenunen kedua dalam subtema Ketuhanan yang memuat simbol kuwasa tersebut. Bener saka kang lagi kuwasa iku uga ana rong warna, yakuwi kang cocog karo benering Pangeran lan kang ora cocog karo benering Pangeran. (Soeharto, 1987: 8)

a) Langkah simbolik

Secara semantis, simbol kuwasa dalam unen-unen 
tersebut memiliki arti kuasa. Kutipan Bener saka kang lagi kuwasa iku uga ana rong warna, yakuwi kang cocog karo benering Pangeran lan kang ora cocog karo benering Pangeran dapat diterjemahkan menjadi Benar menurut yang sedang berkuasa juga ada dua macam, yaitu yang sesuai dengan kebenaran dari Tuhan dan yang tidak sesuai dengan kebenaran Tuhan. Berdasarkan hal tersebut, simbol kuwasa dalam unenunen ini memiliki makna berkuasa

b) Langkah hermeneutik

Secara hermeneutik kalimat Bener saka kang lagi kuwasa iku uga ana rong warna, yakuwi kang cocog karo benering Pangeran lan kang ora cocog karo benering Pangeran dapat dimaknai adanya dua macam kebenaran yang berasal dari orang yang sedang berkuasa. Sesuai dengan kebenaran Tuhan atau berseberangan dengan kebenaran Tuhan.

c) Langkah filosofis

Benar menurut yang sedang berkuasa juga ada dua macam, yaitu yang sesuai dengan kebenaran dari Tuhan dan yang tidak sesuai dengan kebenaran Tuhan. Secara hermeneutik telah disebutkan bahwa terdapat dua macam kebenaran yang berasal dari orang yang sedang berkuasa, yakni sesuai dengan kebenaran Tuhan atau berseberangan dengan kebenaran Tuhan. Secara filosofis, pernyataan ini mendukung unen-unen dalam pertanyaan yang pertama.
Unen-unen yang pertama, secara filosofis menunjukkan bahwa kebenaran menurut penguasa ada dua yakni kebenaran menurut Tuhan dan kebenaran menurut dirinya sendiri. Dengan demikian, unen-unen ini menjadi penegas unen-unen sebelumnya, bahwa kebenaran yang dimiliki oleh orang yang sedang berkuasa mempunyai dua sisi. Satu sisi penguasa berlaku benar sesuai kebenaran yang berasal dari Tuhan. Satu sisi penguasa bisa bertindak benar sesuai ukuran kebenarannya sendiri.

\section{b. Kebangsaan}

1) Simbol penguwasa

Berikut adalah kutipan unenunen dalam subtema Kebangsaan yang memuat simbol penguwasa tersebut. Negara bisa tentrem lamun murah sandhang kalawan pangan, marga para kawula padha seneng nyambut karya, lan ana penguwasa kang darbe sipat berbudi bawa leksana (Soeharto, 1987: 108). Pembahasan unen-unen tersebut dilakukan dengan hermeneutik Ricoeur sebagai berikut.

a) Langkah simbolik

Simbol penguwasa terdapat dalam kalimat berikut Negara bisa tentrem lamun murah sandhang kalawan pangan, marga para kawula padha seneng nyambut karya, lan ana penguwasa kang darbe sipat berbudi bawa leksana. Secara semantis, kalimat tersebut dapat diterjemahkan sebagai berikut. Negara itu dapat tenteram apabila murah sandang dan pangan, sebab rakyatnya gemar bekerja, dan ada penguasa 
yang mempunyai sifat adil dan berjiwa mulia. Simbol penguwasa dalam unen-unen ini berarti penguasa.

b) Langkah hermeneutik

Struktur semantis Negara itu dapat tenteram apabila murah sandang dan pangan, sebab rakyatnya gemar bekerja dan ada penguasa yang mempunyai sifat adil dan berjiwa mulia membawa pada langkah kedua. Secara hermeneutik, pemimpin sebagai penguasa akan memberikan pengaruh terhadap keadaan negara yang dikuasainya. Apabila pemimpin yang menguasai negara memiliki sifat adil dan berjiwa mulia, negara dapat menjadi tenteram, murah sandang pangan dan rakyatnya gemar bekerja.

c) Langkah filosofis

Secara hermeneutik, pemimpin sebagai penguasa dapat memberikan pengaruh terhadap keadaan negara yang dikuasainya. Dengan demikian, pemimpin yang ideal adalah pemimpin yang memiliki sifat adil dan berjiwa mulia. Melalui kepemimpinannya rakyat merasakan keadaan ekonomi yang baik, yakni murah sandang pangan. Pemimpin yang ideal juga mampu memberikan pekerjaan kepada rakyatnya. Apabila rakyat dapat bekerja dan memperoleh upah, upah pekerjaan tersebut lebih dari cukup untuk membeli sandang dan pangan yang murah, negara akan menjadi tenteram. Dengan demikian, pemimpin yang baik adalah pemimpin yang adil, berjiwa mulia, mampu memberi pekerjaan kepada rakyat dan mampu menjaga kestabilan ekonomi negara.

2) Simbol penguwasa

Berikut adalah kutipan unenunen yang memiliki simbol penguwasa. Penguwasa iku kudu gawe tentrem para kawulane, marga yen ora mengkono bisa dadi kawula ngrebut negara. (Soeharto, 1987: 110)

a) Langkah simbolik

Unen-unen yang berbunyi Penguwasa iku kudu gawe tentrem para kawulane, marga yen ora mengkono bisa dadi kawula ngrebut Negara pada tahap ini dibahas secara semantis. Secara semantis unenunen tersebut dapat diartikan sebagai penguasa itu harus membuat tentram rakyatnya, sebab apabila tidak demikian, rakyatnya akan merebut kekuasaan dalam negara itu. Dengan demikian, penguwasa dalam hal ini memiliki arti simbolik sebagai penguasa.

b) Langkah hermeneutik

Struktur semantis penguasa itu harus membuat tentram rakyatnya, sebab apabila tidak demikian, rakyatnya akan merebut kekuasaan dalam negara itu dibawa ke tahap hermeneutik. Secara hermeneutik, pemimpin yang ideal adalah penguasa yang membuat tenteram hati rakyat. Ketenteraman di hati rakyat ini akan mengakibatkan keadaan negara dalam kondisi aman. Sementara itu, apabila pemimpin yang sedang berkuasa tidak mampu membuat tenteram hati rakyatnya, dimungkinkan rakyat akan merebut kekuasaan pemimpin tersebut.

c) Langkah filosofis

Secara hermeneutik, pemimpin yang ideal adalah 
penguasa yang membuat tenteram hati rakyat. Secara filosofis, pemimpin yang ideal adalah pemimpin yang mampu menjaga ketenteraman rakyat berpengaruh terhadap keadaan aman suatu negara. Keadaan aman akan menyebabkan kemajuan pembangunan negara. Kemajuan pembangunan negara dapat berakibat pada kesejahteraan rakyatnya. Selama rakyat berada dalam keadaan aman dan sejahtera, negara akan jauh dari kekacauan dan perebutan kekuasaan.

3) Simbol kuwasa

Berikut adalah kutipan unenunen yang memiliki simbol penguwasa. Yen wong becik kang kuwasa, kabeh kang ala didandani lamun kena, dene yen ora kena disingkirake, mundhak nulari (cuplak andhengandheng) (Soeharto, 1987: 114)

a) Langkah simbolik

Unen-unen yang menyebutkan Yen wong becik kang kuwasa, kabeh kang ala didandani lamun kena, dene yen ora kena disingkirake, mundhak nulari (cuplak andheng-andheng) secara semantik dapat diartikan apabila orang baik yang berkuasa, semua yang jelek sedapat mungkin akan diperbaiki, jikalau tidak dapat diperbaiki akan disingkirkan supaya tidak menular. Dengan demikian, simbol kuwasa memiliki arti berkuasa.

b) Langkah hermeneutik Secara semantik unen-unen tersebut berarti apabila orang baik yang berkuasa, semua yang jelek sedapat mungkin akan diperbaiki, jikalau tidak dapat diperbaiki akan disingkirkan supaya tidak menular. Secara hermeneutik dapat disebutkan bahwa pemimpin yang baik berusaha memperbaiki kekurangan. Kekurangan yang tidak dapat diperbaiki akan disingkirkan. Hal ini untuk menjaga kebaikan yang sudah ada agar tidak tertular oleh kekurangan atau keburukan yang ada.

c) Langkah filosofis

Secara hermeneutik disebutkan bahwa pemimpin yang baik berusaha memperbaiki kekurangan. Kekurangan yang tidak dapat diperbaiki akan disingkirkan. Hal ini untuk menjaga kebaikan yang sudah ada agar tidak tertular oleh kekurangan atau keburukan yang ada. Secara filosofis, hal ini menandakan bahwa pemimpin yang ideal adalah penguasa yang senantiasa mau memperbaiki keburukan dan kekurangan. Keburukan dan keurangan yang tidak dapat diperbaiki akan dibuang.

4) Simbol kuwasa

Berikut adalah kutipan unenunen yang memiliki simbol kuwasa . Wataking manungsa $i k u$ kepengin kuwasa, nanging Pangeran iku bakal maringi penguwasa miturut karsaning Pangeran pribadi (Soeharto, 1987: 116)

a) Langkah simbolik

Unen-unen

yang

menyebutkan Wataking

manungsa iku kepengin

kuwasa, nanging Pangeran 
iku bakal maringi penguwasa miturut karsaning Pangeran pribadi dapat diartikan secara semantis. Secara semantis, unen-unen tersebut berarti sifat manusia itu ingin berkuasa, tetapi Tuhan akan memberi kekuasaan sesuai dengan kehendak Tuhan sendiri. Dengan demikian, simbol kuwasa dalam unenunen ini memiliki arti berkuasa.

b) Langkah hermeneutik

Secara semantis, unen-unen tersebut berarti sifat manusia itu ingin berkuasa, tetapi Tuhan akan memberi kekuasaan sesuai dengan kehendak Tuhan sendiri. Secara hermeneutik, dapat dimaknai bahwa manusia memiliki sifat dan keinginan untuk berkuasa. Kekuasaan yang dimiliki oleh manusia sesuai dengan kehendak Tuhan.

c) Langkah filosofis

Secara hermeneutik, unenunen tersebut dimaknai bahwa manusia memiliki sifat dan keinginan untuk berkuasa. Kekuasaan yang dimiliki oleh manusia sesuai dengan kehendak Tuhan. Dengan demikian, secara filosofis dapat disebutkan bahwa kekuasaan manusia pada dasarnya adalah sebuah amanah dari Tuhan. Kekuasaan manusia bergantung pada kekuasaan yang diberikan Tuhan. Seberapapun usaha manusia untuk menjadi penguasa, apabila Tuhan tidak menghendaki niscaya tidak akan menjadi penguasa. Demikian juga sebaliknya, apabila Tuhan menghendaki seseorang untuk menjadi penguasa di suatu negara, niscaya orang tersebut akan menjadi penguasa dengan cara yang tidak disangkasangka.

5) Simbol penguwasa

Berikut adalah kutipan unenunen yang memiliki simbol penguwasa. Lamun sira darbe penguwasa aja sira luru aleman, jalaran iku bakal ketemu pituwase kang ora prayoga (Soeharto, 1987: 118)

a) Langkah simbolik

Unen-unen yang menyebutkan Lamun sira darbe penguwasa aja sira luru aleman, jalaran iku bakal ketemu pituwase kang ora prayoga dapat diartikan secara semantis. Secara semantis arti dari unen-unen tersebut adalah jikalau engkau menjadi penguasa janganlah hanyalah ingin dipuji-puji saja, sebab hal yang demikian itu berakibat tidak baik. Dengan demikian, simbol penguwasa dapat diartikan sebagai penguasa.

b) Langkah hermeneutik

Secara semantis arti dari unen-unen tersebut adalah jikalau engkau menjadi penguasa janganlah hanyalah ingin dipuji-puji saja, sebab hal yang demikian itu berakibat tidak baik. Secara hermeneutik, unen-unen tersebut dapat berarti penguasa yang senang dipuji memiliki kecenderungan memihak pada orang yang memuji. Keberpihakan ini menyebabkan ketidakadilan.

c) Langkah filosofis

Secara hermeneutik, unenunen tersebut dapat berarti 
penguasa yang senang dipuji memiliki kecenderungan memihak pada orang yang memuji. Secara filosofis dapat dijelaskan bahwa, pemimpin yang senang dipuji akan memiliki kecenderungan untuk anti terhadap kritik. Pemimpin model seperti ini cenderung tidak adil. Ia hanya akan mendengarkan hal-hal yang menyenangkan dan menutup mata pada kekurangankekurangan yang seharusnya diperbaiki. Pemimpin yang baik harus waspada pada pujian agar dapat berlaku adil.

6) Simbol penguwasa

Berikut adalah kutipan unenunen yang memiliki simbol penguwasa. Lamun ana penguwasa asale saka wong ala, iku ora lawas bakal konangan alane, sebab kabeh mau wis kawaka saka tumindake penguwasa mau. (Soeharto, 1987: 120)

a) Langkah simbolik

Unen-unen yang memiliki simbol penguwasa. Lamun ana penguwasa asale saka wong ala, iku ora lawas bakal konangan alane, sebab kabeh mau wis kawaka saka tumindake penguwasa mau. Unen-unen tersebut secara semantis dapat diartikan menjadi jikalau ada penguasa yang berasal dari orang yang tidak baik, tidak lama pasti akan ketahuan jeleknya, sebab semuanya akan tampak dari tindakan penguasa itu. Dengan demikian, simbol penguwasa dapat diartikan sebagai penguasa.

b) Langkah hermeneutik

Secara semantis dapat diartikan menjadi jikalau ada penguasa yang berasal dari orang yang tidak baik, tidak lama pasti akan ketahuan jeleknya, sebab semuanya akan tampak dari tindakan penguasa itu. Secara hermeneutik, hal tersebut dapat dijelaskan sebagai berikut. Pemimpin yang berasal dari golongan orang yang berperangai buruk akan menampakkan keadaan aslinya, yakni perangai yang buruk. Perangai yang buruk tersebut muncul melalui perbuatan dan tindakan yang dilakukan oleh pemimpin tersebut.

c) Langkah filosofis

Secara hermeneutik, dijelaskan bahwa pemimpin yang berasal dari golongan orang yang berperangai buruk akan menampakkan keadaan aslinya, yakni perangai yang buruk. Perangai yang buruk tersebut muncul melalui perbuatan dan tindakan yang dilakukan oleh pemimpin tersebut. Secara filosofis dapat dijelaskan bahwa pemimpin yang buruk tidak dapat menyembunyikan keburukannya. Keburukankeburukan ituakan muncul dalam perilaku, tindak-tanduk dan kebijakan yang dibuat oleh pemimpin tersebut. Munculnya keburukan dari perangai asli yang buruk tersebut, tidak membutuhkan waktu yang lama. Keburukankeburukan pemimpin tersebut akan berakibat pada keadaan rakyat dan negara. Keadaan rakyat dan negara yang dipimpin oleh pemimpin yang buruk akan terjerumus pada kekacauan tatanan masyarakat dan negara. 
7) Simbol kuwasa

Berikut adalah kutipan unenunen yang memiliki simbol kuwasa. Wong ala samangsa kuwasa aja dicedhaki, sebab mbilaeni, saya mundhak angkara murkane, lan meneh bakal dienggo srana menangake kanga ala mau (Soeharto, 1987: 128)

a) Langkah simbolik

Unen-unen pada kalimat Wong ala samangsa kuwasa aja dicedhaki, sebab mbilaeni, saya mundhak angkara murkane, lan meneh bakal dienggo srana menangake kanga ala mau dapat diartikan secara semantis. Secara semantis, unen-unen tersebut dapat diartikan menjadi orang jahat kalau berkuasa jangan didekati, sebab berbahaya; ia akan tambah angkara murkanya, lagipula engkau akan dipakai sebagai sarana untuk memenangkan kejahatan itu. Dengan demikian, kuwasa dalam hal ini berarti berkuasa.

b) Langkah hermeneutik

Secara semantis, unen-unen tersebut diartikan sebagai orang jahat kalau berkuasa jangan didekati, sebab berbahaya; ia akan tambah angkara murkanya, lagipula engkau akan dipakai sebagai sarana untuk memenangkan kejahatan itu. Secara hermeneutik dapat dijelaskan bahwa pemimpin yang jahat tidak perlu didekati. Pemimpin jahat adalah pemimpin yang berbahaya. Orang-orang yang berada di dekatnya adalah orang-orang yang akan menjadi alat untuk memenangkan kejahatan yang dilakukannya. c) Langkah filosofis

Secara hermeneutik dapat dijelaskan bahwa pemimpin yang jahat tidak perlu didekati. Pemimpin jahat adalah pemimpin yang berbahaya. Orang-orang yang berada di dekatnya adalah orang-orang yang akan menjadi alat untuk memenangkan kejahatan yang dilakukannya. Secara filosofis dapat dijelaskan sebagai berikut. Pemimpin yang jahat akan membawa dampak buruk bagi orang-orang dekatnya. Orang-orang terdekat hanya akan dijadikan alat untuk membenarkan kejahatan yang dilakukannya. Sementara dampak bagi orang-orang jauh yang masih berada di wilayah kekuasaannya, dapat menjadi korban dari tindak kejahatannya.

8) Simbol kuwasa

Berikut adalah kutipan unenunen yang memiliki simbol kuwasa. Wong ala iku lamun kuwasa banjur sawiyah-wiyah nguja hawa napsune, lan uga ngagung-agungake penguwasane, mula aja nganti won gala bisa nyekel penguwasa (Soeharto, 1987: 128)

a) Langkah simbolik

Unen-unen pada kalimat Wong ala iku lamun kuwasa banjur sawiyah-wiyah nguja hawa napsune, lan uga ngagung-agungake

penguwasane, mula aja nganti won gala bisa nyekel penguwasa dapat secara semantis. Secara semantis, unen-unen tersebut dapat diartikan menjadi orang jahat kalau berkuasa akan 
bertindak sewenang-wenang, melampiaskan hawa nafsunya dan membanggakan kekuasaannya. Oleh karena itu jangan sampai ada orang jahat memegang kekuasaan. Dengan demikian, simbol kuwasa tersebut berarti berkuasa.

b) Langkah hermeneutik

Secara semantis, unen-unen tersebut dapat diartikan menjadi orang jahat kalau berkuasa akan bertindak sewenang-wenang,

melampiaskan hawa nafsunya dan membanggakan kekuasaannya. Oleh karena itu jangan sampai ada orang jahat memegang kekuasaan. Secara hermeneutik, unenunen tersebut dapat dijelaskan sebagai berikut. Pilihlah pemimpin yang baik. Pemimpin yang jahat hanya akan membanggakan kekuasaan, melampiaskan hawa nafsu, dan bertindak sewenang-wenang.

c) Langkah filosofis

Secara hermeneutik, unenunen tersebut berarti petunjuk untuk memilih pemimpin yang baik. Pemimpin yang jahat hanya akan membanggakan kekuasaan, melampiaskan hawa nafsu, dan bertindak sewenangwenang. Secara filosofis dapat dijelaskan sebagai berikut. Pemimpin jahat dalam unen-unen ini merupakan penegasan terhadap unen-unen sebelumnya. Memilih pemimpin yang ideal sesuai kebenaran Tuhan dan kebaikannya pada sesama merupakan hal utama. Unenunen ini sekaligus menjadi petunjuk bagi calon pemimpin untuk tidak berlaku buruk sebagaimana yang telah disebutkan sebelumnya, yakni berlaku jahat, membanggakan kekuasaan, melampiaskan hawa nafsu, dan bertindak sewenang-wenang.

9) Simbol kuwasa

Berikut adalah kutipan unenunen yang memiliki simbol kuwasa. Wong ala yen bisa kuwasa, kanga ala iku diarani becik, kosok baline yen wong becik kang kuwasa, kang becik iku kang ditindakake (Soeharto, 1987: 128)

a) Langkah simbolik

Unen-unen pada kalimat Wong ala yen bisa kuwasa, kanga ala iku diarani becik, kosok baline yen wong becik kang kuwasa, kang becik iku kang ditindakake dapat diartikan secara semantis. Secara semantis, arti dari kalimat tersebut adalah sebagai berikut. Orang yang jahat kalau dapat berkuasa, segala yang jelek dikatakan baik, sebaliknya kalau ada orang baik-baik yang berkuasa, maka hal-hal yang baiklah yang dijalankan. Dengan demikian, simbol kuwasa berarti berkuasa.

b) Langkah hermeneutik

Secara semantis, disebutkan bahwa Orang yang jahat kalau dapat berkuasa, segala yang jelek dikatakan baik, sebaliknya kalau ada orang baik-baik yang berkuasa, maka hal-hal yang baiklah yang dijalankan. Secara hermeneutik dapat dijelaskan sebagai berikut. Pemimpin jahat yang berkuasa akan melihat kebaikan dan 
keburukan

pertimbangan

berdasarkan

dan

kepentingan

pribadi.

Sementara pemimpin yang baik akan menjalankan halhal yang baik sesuai dengan pertimbangan kebaikan dan kebenaran yang diyakini akan berdampak baik bagi masyarakat umum.

c) Langkah filosofis

Secara hermeneutik sudah dijelaskan bahwa pemimpin jahat yang berkuasa akan melihat kebaikan dan keburukan berdasarkan pertimbangan dan kepentingan pribadi. Sementara pemimpin yang baik akan menjalankan halhal yang baik sesuai dengan pertimbangan kebaikan dan kebenaran yang diyakini akan berdampak baik bagi masyarakat umum. Secara filosofis hal ini dapat dijelaskan sebagai berikut. Pemimpin jahat dan pemimpin baik memiliki pertimbangan, penilaian dan kepentingan yang berbeda dalam memandang kebaikan dan keburukan. Pemimpin yang baik akan mementingkan kemaslahatan. Sementara pemimpin jahat akan melakukan kejahatan demi kesenangan pribadi tanpa mempedulikan akibat yang terjadi.

2. Wewaler (Pantangan)

a. Kemanusiaan

1) Simbol kuwasa

Berikut adalah kutipan unenunen yang memiliki simbol kuwasa. Aja dumeh kuwasa, mundhak kena walade (Soeharto, 1987: 184) a) Langkah simbolik

Unen-unen pada kalimat Aja dumeh kuwasa, mundhak kena walade dapat diartikan secara semantis. Secara semantis, Aja dumeh kuwasa, mundhak kena walade berarti jangan sok kuasa, nanti kena akibatnya. Dengan demikian, simbol kuwasa dalam unenunen ini berarti kuasa.

b) Langkah hermeneutik Secara semantis, Aja dumeh kuwasa, mundhak kena walade berarti jangan sok kuasa, nanti kena akibatnya. Secara hermeneutik dapat dijelaskan sebagai berikut. Pemimpin yang sedang berkuasa dilarang untuk menyombongkan kekuasaannya. Kesombongan ini akan mengakibatkan konsekuensi yang buruk.

c) Langkah filosofis

Secara hermeneutik sudah dijelaskan bahwa pemimpin yang sedang berkuasa dilarang untuk menyombongkan kekuasaannya. Kesombongan ini akan mengakibatkan konsekuensi yang buruk. Secara filosofis dapat disebutkan sebagai berikut. Pemimpin yang sombong akan dijauhi oleh bawahannya. Pemimpin yang sombong akan dibenci oleh bawahannya. Konsekuen logis dari aja dumeh pada dasarnya untuk mengingatkan bahwa suatu saat keadaan dapat berubah. Oleh sebab itu, ketika masih berkuasa seyogyanya berkuasalah dengan berdasar pada kebenaran dan kebaikan. Hal ini akan lebih aman manakala ada perubahan zaman yang 
menyebabkan pemimpin tersebut tidak berkuasa lagi.

b. Kebangsaan

1) Simbol penguwasa

Berikut adalah kutipan unenunen yang memiliki simbol penguwasa. Aja seneng yen lagi darbe penguwasa, serik yen lagi ora darbe penguwasa, jalaran kuwi bakal ana bebendune dhewe-dhewe (Soeharto, 1987: 188)

a) Langkah simbolik

Unen-unen yang
menyebutkan bahwa aja seneng yen lagi darbe penguwasa, serik yen lagi ora darbe penguwasa, jalaran kui bakal ana bebendune dhewedhewe dapat diartikan secara semantis. Secara semantis, unen-unen tersebut berarti jangan hanya senang kalau sedang mempunyai kekuasaan, sakit hati kalau sedang tidak mempunyai kekuasaan, sebab hal itu akan ada akibatnya sendiri-sendiri. Dengan demikian, simbol penguwasa berarti kekuasaan.

b) Langkah hermeneutik

Secara semantis, unen-unen tersebut berarti jangan hanya senang kalau sedang mempunyai kekuasaan, sakit hati kalau sedang tidak mempunyai kekuasaan, sebab hal itu akan ada akibatnya sendiri-sendiri. Secara hermeneutik unen-unen tersebut dapat dijelaskan sebagai berikut. Senang saat sedang berkuasa dan sedih saat tidak berkuasa pada dasarnya adalah pilihan bagi pemimpin. Pemimpin yang baik adalah pemimpin yang amanah saat berkuasa dan merasa lega saat tidak berkuasa.

c) Langkah filosofis

Secara hermeneutik unenunen tersebut dapat dijelaskan sebagai berikut. Senang saat sedang berkuasa dan sedih saat tidak berkuasa pada dasarnya adalah pilihan bagi pemimpin. Pemimpin yang baik adalah pemimpin yang amanah saat berkuasa dan merasa lega saat tidak berkuasa. Secara filosofis dapat dijelaskan sebagai berikut. Kesenangan pemimpin seharusnya kesenangan rakyatnya. Apabila rakyatnya merasakan kesejahteraan pemimpin ikut berbahagia. Apabila rakyatnya menderita seharusnya pemimpin juga ikut bersedih. Kegembiraan dan kesedihan pemimpin bukan lagi berdasar pada keadaan pribadi melainkan berdasar pada keadaan masyarakatnya.

Demikianlah konsep kepemimpinan Soeharto yang termaktub dalam Butir-butir Budaya Jawa. Secara ringkas dapat disebutkan sebagai berikut. Konsep kepemimpinan Soeharto meliputi Pituduh (petunjuk) dan Wewaler (larangan). Konsep kepemimpinan dalam Pituduh berkaitan dengan masalah ketuhanan dan kebangsaan. Konsep kepemimpinan dalam wewaler berkaitan dengan kemanusaiaan dan kebangsaan. Pada Pituduh, Soeharto bermaksud memberikan gambaran mengenai hal-hal yang perlu dilakukan oleh seorang pemimpin. Sementara pada wewaler merupakan pantangan atau larangan terhadap hal-hal yang tidak diperkenankan dilakukan oleh pemimpin.

Konsep kepemimpinan dalam pituduh yang masuk ke dalam kategori ketuhanan memiliki dua petunjuk kepemimpinan yakni 1) jadilah penguasa yang berlaku 
baik dan benar, 2) Kebenaran Tuhan menjadi dasar kebenaran penguasa. Konsep kepemimpinan dalam pituduh yang masuk ke dalam kategori kebangsaan meliputi 1) pemimpin yang baik adalah pemimpi yang adil, berjiwa mulia, mampu memberi pekerjaan kepada rakyat, 2) Pemimpin yang baik adalah pemimpin yang mampu menenteramkan hati rakyat, 3) Pemimpin yang baik mau dan mampu memperbaiki kekurangan dan keburukan, 4) kepemimpinan adalah amanah dari Tuhan, 5) Pemimpin yang baik waspada terhadap pujian, 6) pemimpin yang baik waspada terhadap perangai buruk, 7) Pemimpin jahat adalah pemimpin yang berbahaya, 8) Memilih pemimpin yang baik bukan pemimpin jahat, 9) pemimpin yang jahat akan menyatakan kejahatan adalah kebaikan. Konsep kepemimpinan dalam Wewaler meliputi dua kategori, yakni kemanusiaan dan kebangsaan. Kategori larangan dalam hal kemanusiaan meliputi larangan terhadap pemimpin yakni pemimpin dilarang sombong. Larangan dalam hal kebangsaan menunjukkan bahwa pemimpin yang baik menyandarkan kesenangan dan kesedihannya atas dasar kesenangan dan kesedihan rakyatnya, bukan berdasar kesenangan dan kesedihan pribadi.

\section{PERSANTUNAN}

Penulis mengucapkan terima kasih kepada berbagai pihak yang telah membantu dalam proses penelitian ini.

\section{SIMPULAN}

Berdasar hasil penelitian yang telah dilakukan, kesimpulan dari penelitian ini adalah sebagai berikut. Konsep kepemimpinan Soeharto yang termaktub dalam Butir-butir Budaya Jawa meliputi Pituduh (petunjuk) dan Wewaler (larangan). Konsep kepemimpinan dalam Pituduh berkaitan dengan masalah ketuhanan dan kebangsaan. Konsep kepemimpinan dalam wewaler berkaitan dengan kemanusiaan dan kebangsaan. Pada Pituduh, Soeharto bermaksud memberikan gambaran mengenai hal-hal yang perlu dilakukan oleh seorang pemimpin. Sementara pada wewaler merupakan pantangan atau larangan terhadap hal-hal yang tidak diperkenankan dilakukan oleh pemimpin. Secara detil dapat disebutkan sebagai berikut.

1. Konsep kepemimpinan dalam pituduh yang masuk ke dalam kategori ketuhanan memiliki dua petunjuk kepemimpinan yakni (1) jadilah penguasa yang berlaku baik dan benar, (2) Kebenaran Tuhan menjadi dasar kebenaran penguasa. Konsep kepemimpinan dalam pituduh yang masuk ke dalam kategori kebangsaan meliputi (1) pemimpin yang baik adalah pemimpi yang adil, berjiwa mulia, mampu memberi pekerjaan kepada rakyat, (2) Pemimpin yang baik adalah pemimpin yang mampu menenteramkan hati rakyat,

Pemimpin yang baik mau dan mampu memperbaiki kekurangan dan keburukan, (4) kepemimpinan adalah amanah dari Tuhan, (5) Pemimpin yang baik waspada terhadap pujian, (6) pemimpin yang baik waspada terhadap perangai buruk, Pemimpin jahat adalah pemimpin yang berbahaya, (8) Memilih pemimpin yang baik bukan pemimpin jahat, (9) pemimpin yang jahat akan menyatakan kejahatan adalah kebaikan.

2. Konsep kepemimpinan dalam Wewaler meliputi dua kategori, yakni kemanusiaan dan kebangsaan. Kategori larangan dalam hal kemanusiaan meliputi larangan terhadap pemimpin yakni pemimpin dilarang sombong. Larangan dalam hal kebangsaan menunjukkan bahwa pemimpin yang baik menyandarkan kesenangan dan kesedihannya atas dasar kesenangan dan kesedihan rakyatnya, bukan berdasar kesenangan dan kesedihan pribadi. 


\section{PERSANTUNAN}

Peneliti mengucapkan terima kasih kepada berbagai pihak yang telah membantu dalam proses penelitian ini.

\section{DAFTAR PUSTAKA}

Indraningsih. 2011. 'Hermeneutika Paul Ricoeur dan Penerapannya Pada Pemaknaan Simbol dalam Roman "Rafilus" Karya Budi Darma'. Jurnal Filsafat Vol.21, Nomor 2, hlm. 119-120.

Soeharto. 1987. Butir-Butir Budaya Jawa. Jakarta: Yayasan Purna Bhakti Pertiwi

Suseno, Franz Magnis. Etika Jawa: Sebuah Analisa Falsafi tentang Kebijaksanaan Hidup Jawa. Jakarta: Gramedia. 